\title{
Multi-Residue Analysis of Organophosphorus Pesticides in Vegetable Using GC-MS
}

\author{
Dhia Eldin Elhag, Babeker S. Abdalla, Suliman A. Suliman, Imtinan Ali \\ Institute of Research, UMST University, Khartoum, Sudan \\ Email:magied20@gmail.com
}

How to cite this paper: Elhag, D.E., Abdalla, B.S., Suliman, S.A. and Ali, I. (2017) Multi-Residue Analysis of Organophosphorus Pesticides in Vegetable Using GC-MS. Journal of Agricultural Chemistry and Environment, 6, 232-241

https://doi.org/10.4236/jacen.2017.64016

Received: August 27, 2017

Accepted: November 27, 2017

Published: November 30, 2017

Copyright $\odot 2017$ by authors and Scientific Research Publishing Inc. This work is licensed under the Creative Commons Attribution International License (CC BY 4.0).

http://creativecommons.org/licenses/by/4.0/

\begin{abstract}
This study investigates the levels of pesticide residues in Cucumbers (Cucumis sativus), potatoes (Solanum tuberosum subsp. Tuberosum) and tomatoes (Lycopersicon esculentum). The samples were minced in a food processor initially subjected to extraction followed by cleanup using solid phase extraction (SPE) column. Separation was performed on a GC capillary column (Rtx-5 $\mathrm{ms}-30 \mathrm{~m} \times 0.25 \mathrm{~mm} \times 0.25 \mu \mathrm{m}$ ). The sample was injected by using splitless mode, helium as the carrier gas followed by quadrupole mass spectrometry detection. The mobile phase flow rates, column temperatures, and MS parameters were all optimized to reach high sensitivity and selectivity. Seven pesticides were detected in tomatoes sample, six in cucumber and four in potatoes samples. The findings indicate risks and concerns for public health.
\end{abstract}

\section{Keywords}

Pesticides, Organophosphorus, Malathion, Environmental Exposure

Vegetables, Gas Chromatography-Mass Spectrometry

\section{Introduction}

Pesticides constitute any substance or mixture of substances, such as insecticides, fungicides, rodenticides, insect repellants, weed killers, antimicrobials intended for preventing, destroying, or mitigating any pest. Pesticides are linked to a variety of diseases such as cancer [1] [2]. Their mode of action is by targeting systems or enzymes in the pests which may be identical or very similar to systems or enzymes in human beings and therefore, they pose risks to human health and the environment through their toxicity persistence, mobility, degradation, bioaccumulation, volatility, and leaching [3] [4]. The greater use of pesticides for high agricultural production has led to increased pollution of soil, water and air [5] [6]. The fate of the pesticides is controlled by the chemical and 
physical properties and by the natural processes that might take place such as accumulation, degradation or volatility. Regulations to identify and quantify pesticides are constantly changing to ensure increased food safety, making the screening and routine quantitation of pesticide residues an important and demanding application in food safety. WHO and the Expert Committee on Pesticide Residues in Food (PRiF) had issued a number of guidelines that regulate the use of pesticides [7] [8] [9].

The toxicity of pesticides had been accelerated by their improper use and lack of awareness of their potential risks. Many people die or severely affected from pesticides poisoning [10] [11]. More selective and safer pesticides and new chemical groups emerged had been introduced in the last four decades to ensure selectivity and minimal side effects [12] [13].

A plethora of analytical and spectroscopic methods had been introduced and utilized for the determination of pesticides residues [14]-[18]. Advances in GCMS instrumentation had been introduced to increase the sensitivity, mass accuracy determination, resolution and the detectability of this technique. LC/MS/MS can be used to simultaneously monitor hundreds of potential contaminants-including those difficult to detect by GC [19] [20]. While the MS/MS detector allows for specific, sensitive detection of the pesticide species, the LC column specifications such as particle size is vital to ensure the highest quality data. Ultra-high pressure LC (UHPLC) can also be used with MS/MS detection for monitoring pesticide residues. UHPLC allows for higher sample throughput when used in conjunction with a highly efficient $<2 \mu \mathrm{m}$ particle size column [21].

\subsection{Experimental}

\section{Sample Preparation and Processing}

Cucumbers (Cucumis sativus), potatoes (Solanum tuberosum subsp. Tuberosum) tomatoes (Lycopersicon esculentum) samples were bought from a local vendor, Khartoum, Sudan. Organophousphorus pesticides and malathion standard reference material were supplied by Shimadzu, Japan.

\section{Standards}

The pesticide standards used in this study are: Dichlorvos, Fenobucarb, Simazine, Propyzamide, Diazinon, Fennitrothion, Thiobencarb, Isoprothiolane Isoxathion, Tetrachloroisophthalonitrile (TPN), Chlornitrofen (CNP) (Phosphonothioic acid, phenyl-, O-ethyl O-(4-nitrophenyl) ester EPN and iprobenfos. A mixture of the pesticide standards was prepared with ethyl acetate in the concentration to give a concentration of $0.001 \mathrm{ppm}$. Malathion standard (10 ppm) also was prepared with ethyl acetate.

\subsection{Samples Preparation}

\subsubsection{Extraction of Vegetables Samples for Pesticides Determination}

Sample preparation and extraction were conducted within 24 hours after sampling. $20 \mathrm{~g}$ grams of each of the vegetables were weighed into a conical flask and 
$20 \mathrm{~g}$ of anhydrous sodium sulfate and $5 \mathrm{~g}$ of sodium hydrogen carbonate were added. $100 \mathrm{ml}$ of $1: 1(\mathrm{v} / \mathrm{v})$ ethyl acetate/dichloromethane mixture were added and the mixture was shaken. The content of the conical flask were mixed thoroughly by shaking the conical flask. Another $20 \mathrm{~g}$ of anhydrous sodium sulfate were further added to the content of the flask and $20 \mathrm{~g}$ of sodium hydrogen carbonate were added. Each conical flask was corked tightly and the mixture was shaken thoroughly for $10 \mathrm{~min}$ and was allowed to stand for $3 \mathrm{~h}$. The organic layer was decanted into a $200 \mathrm{ml}$ round bottom flask and evaporated using the rotary evaporator at $40^{\circ} \mathrm{C}$. Finally each sample was dissolved and collected with $2 \mathrm{ml}$ of ethyl acetate and transferred into a $2 \mathrm{ml}$ vial and ready for the clean-up.

\subsubsection{Clean-Up of vegetable Extracts Using Silica Gel}

Solid phase extraction cartridges (SPE) were used to extract the samples. $10 \mathrm{ml}$ of 1:1 ( $/ \mathrm{v})$ ethyl acetate/dichloromethane mixture were used to wet and rinse the cartridges. The $2 \mathrm{ml}$ extract residue in the vial were transferred into the cartridge and the extract vial rinsed (three times) with $2 \mathrm{ml}$ ethyl acetate. The cartridges were eluted with $80 \mathrm{ml}$ portion of ethyl acetate/dichloromethane at a rate of $5 \mathrm{ml} / \mathrm{min}$ into a conical flask as fraction one. Further elution was conducted with $50 \mathrm{ml}$ portion of ethyl acetate/dichloromethane for the second elution. The first and second extract were mixed together. All the fractions of each sample were concentrated to dryness using a rotary evaporator at $40^{\circ} \mathrm{C}$. The extract were dissolved in $2 \mathrm{ml}$ ethyl acetate and collected in a vial for gas chromatograph analysis.

\subsubsection{De-Fattening of the Extract}

The $2 \mathrm{ml}$ extract for pesticides analysis was transferred into a $100 \mathrm{ml}$ separator funnel and $50 \mathrm{ml}$ of 1:1 (v/v) hexane/acetonitrile solution were added. The separator funnels were gradually shaken gently for $3 \mathrm{~min}$ and were allowed to stand for $20 \mathrm{~min}$ so as to allow separation of the organic solvents. The fraction that contained the acetonitrile fractions of the pesticides were collected into a $50 \mathrm{ml}$ beaker, while the other fractions that contained the fat in the hexane solvent phase was discarded. The acetonitrile fraction that contained the pesticides extract was further cleaned-up by using $25 \mathrm{ml}$ of the pure hexane. The acetonitrile fraction was concentrated to dryness using a rotary evaporator at $40^{\circ} \mathrm{C}$. The extract from the de-fattening process were further dissolved using $2 \mathrm{ml}$ of ethyl acetate and collected into a $2 \mathrm{ml}$ vial. The vial containing the pesticides extracts were stored in the refrigerator at $4^{\circ} \mathrm{C}$ for GCMS analysis.

\subsection{GC/MS Conditions for Organophosphorus Pesticides}

The sample was injected by using splitless mode, helium as the carrier gas passed with flow rate $1.69 \mathrm{ml} / \mathrm{min}$, the temperature program was started from $50^{\circ} \mathrm{C}$ with rate $20^{\circ} \mathrm{C} / \mathrm{min}$ to $140^{\circ} \mathrm{C}$ then the rate was changed to $10^{\circ} \mathrm{C} / \mathrm{min}$ reaching $280^{\circ} \mathrm{C}$ as final temperature with 3 minutes as hold time, the injection port temperature was $250^{\circ} \mathrm{C}$, the ion source temperature was $170^{\circ} \mathrm{C}$ and the interface 
temperature was $250^{\circ} \mathrm{C}$.

\subsection{GC/MS Conditions for Malathion}

The sample was injected by using splitless mode, helium was passed with flow rate $1.08 \mathrm{ml} / \mathrm{min}$, the temperature program was started from $150^{\circ} \mathrm{C}$ with rate $10^{\circ} \mathrm{C} / \mathrm{min}$ to $280^{\circ} \mathrm{C}$ as final temperature, the injection port temperature was $290^{\circ} \mathrm{C}$, the ion source temperature was $200^{\circ} \mathrm{C}$ and the interface temperature was $280^{\circ} \mathrm{C}$.

\subsection{Instrument}

The qualitative and quantitative analysis of the sample was carried out by using GM/MS technique model (GC/MS-QP2010-Ultra), Shimadzu Company, Japans with serial number 020525101565SA and capillary column (Rtx-5 ms-30 m $\times$ $0.25 \mathrm{~mm} \times 0.25 \mu \mathrm{m})$.

\section{Results}

The identification of pesticides in foodstuffs is a difficult task, which requires selective techniques for unambiguous confirmation, since interfering species from the matrix often mask the signal of the target compounds. For these reasons, the use of chromatographic techniques coupled with MS detection is highly desirable in order to attain satisfactory results. These techniques enable unequivocal identification and confirmation of target species, unlike less selective detectors (e.g., NPD and ECD), avoiding matrix interferences and both false positives and false negatives.

An amount of $10 \mathrm{ppm}$ of pesticides mixture was injected into the GCMS and the spectra were collected. The sample was analyzed by using scan mode in the range of $60-350 \mathrm{~m} / \mathrm{z}$. The total run time was 20 minutes. Subsequently the vegetables samples were injected separately. The obtained results were recorded and shown in Figure 1 and Table 1. GCMS analysis can be performed in two modes: Single-ion monitoring (SIM): 1 - 4 ions are observed selectively as they provide improved signal-to-noise ratio for ions of interest and Total ion current (TIC): sum of all ions-can be noisy but also captures potential unknown $\mathrm{m} / \mathrm{z}$ ratios. Single-ion monitoring (SIM) was chosen based on spectra of the pesticides taken from a full mass range analysis of a high level standard. The second mode is the total ion current (TIC) and in this mode a scan acquisition allows the ion selection to be monitored post-acquisition.

In the analysis of organophosphorus pesticides, the ions which give the highest abundance in the El mass spectra, were selected for monitoring in GC-MS analysis. Increasing the number of ions monitored will only reduce the overall sensitivity of analysis, thus increasing the detection limit.

The most conventional GC-MS detector for pesticide analysis in vegetables is the single quadrupole as it provides high selectivity, high sensitivity and speed of analysis. 


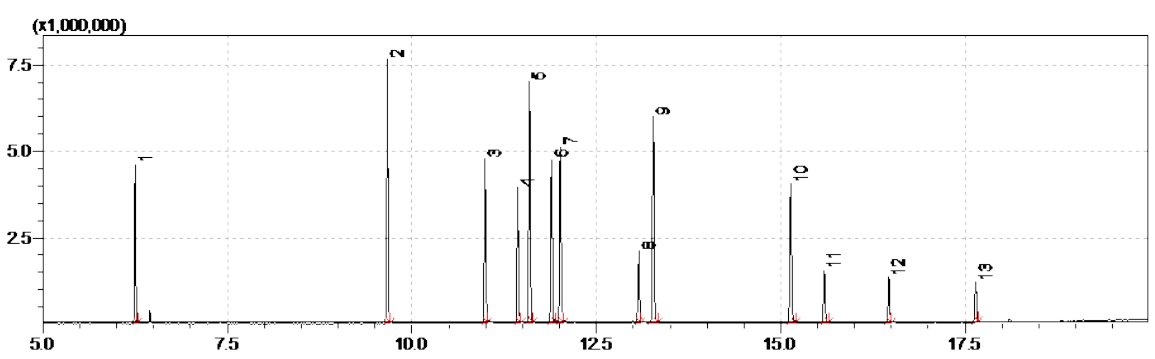

(a)

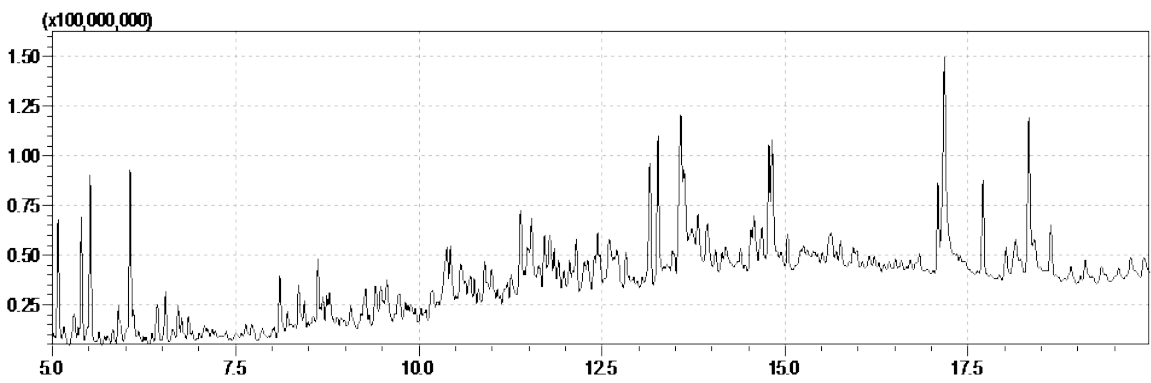

(b)

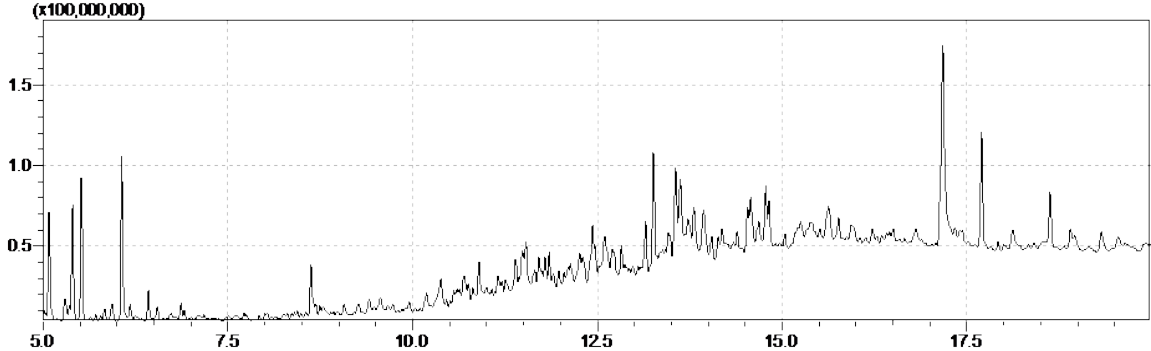

(c)

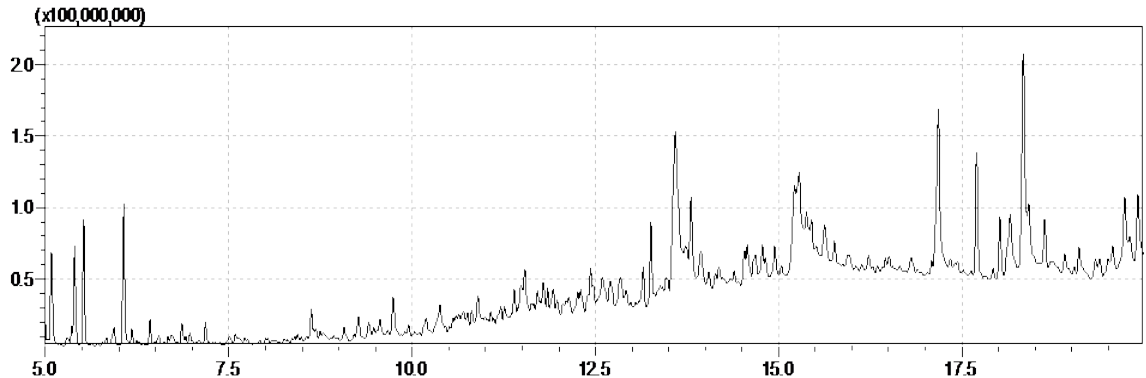

(d)

Figure 1. GC chromatograms of (a) Organophosphorus Pesticides Mixture; (b) Tomatoes sample; (c) Potatoes sample; and (d) Cucumber sample.

The GC chromatogram of the organophosphorus pesticides show sharp, well resolved-noise free peaks whereas the chromatograms of the samples show several background peaks were apparent and associated with noise and this is due to the complex matrix of the samples despite extract cleanup of the sample. Nevertheless, pesticides were detected.

Quantitation of the different levels of the pesticides was achieved by the use of single standard method and the results obtained are depicted in Table 1. 
Table 1. The ions selected for analysis.

\begin{tabular}{ccc}
\hline No & Pesticide & Monitoring ion $(\mathrm{m} / \mathrm{z})$ \\
\hline 1 & Simazine & 201,186 \\
2 & Propyzamide & 255,173 \\
3 & TPN & 266,264 \\
4 & Iprobenfos & 204,91 \\
5 & CNP & 291,217 \\
6 & EPN & 169,157 \\
7 & Thiometon & $127,125,93$ \\
2 & Malathion & $127,125,93$ \\
\hline
\end{tabular}

\section{Malathion}

The ions selected $(127,125,173)$ and the total run time was 16 minutes. The $(\mathrm{m} / \mathrm{z}) 173$ provides a good selectivity and also be monitored with confidence at low levels. Lower mass ions intensities such m/z 125 and 127), m/z 173 are also informative.

The GC chromatogram of malathion is shown in Figure 2 and the amount calculated for the three different samples are shown in Table 2. The quantities of the detected pesticides are shown in Table 2. The insecticide thiometon in the tomatoes sample was above the MRL limit whereas malathion level was below the MRL. In cucumber and potatoes samples neither of the pesticides were detected.

The maximum residue levels for the reported pesticides in the EC [22] database and detected in this study are tabulated in Table 3.

The other detected pesticides. i.e. Tetrachloroisophthalonitrile (TPN), Chlornitrofen (CNP) and (Phosphonothioic acid, phenyl-, O-ethyl O-(4-nitrophenyl) ester) (EPN) are not reported in the EC database but their toxicity had been investigated by different authors [2] [23]-[27].

Multi-residue surveillance of pesticides in vegetables and fruits is an ongoing project for regulatory agencies worldwide. Regulations to identify and quantify pesticides are constantly changing to ensure increased food safety, making the screening and routine quantitation of pesticide residues an important and demanding application in food safety.

The use of GCMS produces very reliable methods for the determination of pesticides at trace level in vegetables. However, matrix interferences can complicate the analysis and compromise the selectivity and specificity of the method. The EU commission has issued guidelines for pesticides analysis that involves the use of MS techniques in order to meet the confirmation requirements. This fact highlights the need for improved sample treatment method. New extraction techniques were introduced for sample treatment that include supercritical fluid extraction, microwave-assisted extraction, solid-phase microextraction, matrix solid-phase dispersion and pressurized fluid extraction-accelerated solvent 


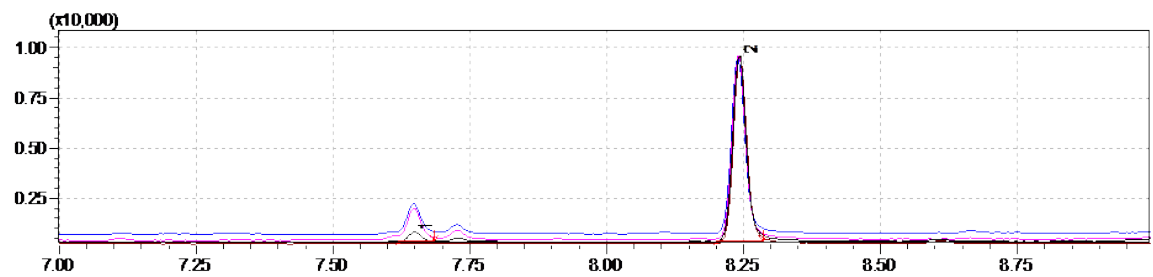

Figure 2. GC Chromatograms of Malathion and thiometon mixture. The relevant MS were collected in the SIM mode. For thiometon, retention time $7.7 \mathrm{~min}$, the ions are $\mathrm{m} / \mathrm{z}=127$ (Blue), $\mathrm{m} / \mathrm{z}=125 \mathrm{M}$ (Pink) and $\mathrm{m} / \mathrm{z}=88$ (Black). For Malathion retention time $8.25 \mathrm{~min}$, the ions are $\mathrm{m} / \mathrm{z}=127$ (Blue), $\mathrm{m} / \mathrm{z}=125 \mathrm{M}$ (Pink) and $\mathrm{m} / \mathrm{z}=88$ (Black).

Table 2. The quantities of the detected pesticides.

\begin{tabular}{cccccc}
\hline ID & Name & Ret. time & Tomatoes & Cucumber & Potatoes \\
\hline 1 & Thiometon & 7.647 & 16.03470 & Not detected & Not detected \\
2 & Malathion & 8.239 & 8.04479 & Not detected & Not detected \\
\hline
\end{tabular}

Table 3. The maximum residue levels of pesticides in the vegetable samples (ug/kg).

\begin{tabular}{ccccc}
\hline Vegetables & Malathion & Propyzamide & Simazine & Isoprothiolane \\
\hline Potatoes & 0.02 & 0.01 & 0.01 & 0.01 \\
Tomatoes & 0.02 & 0.01 & 0.01 & 0.01 \\
Cucumbers & 0.02 & 0.01 & 0.01 & 0.01 \\
\hline
\end{tabular}

extraction. For instance the introduction of QuEChERS had brought about the ease, effectiveness, rapidity, ruggedness and safety to the sample treatment method. Many authors had reported the advantages of the use of QuEChERS in pesticides and multi-residue analysis. Pesticide residue surveillance food and environmental samples is an ongoing project for regulatory bodies worldwide [28] [29] [30].

In pesticides analysis, multi-residue analysis is the common practice. Pesticides comprise a large group of chemicals that differ in their physicochemical properties e.g. polarity molecular size and charge. A single run for such determination may affect the sensitivity of the analysis due to such differences which may jeopardizes the analysis and requires careful optimization of the technique.

An important aspect in pesticides analysis is sample history i.e. the information regarding the time of application i.e. before harvesting and the duration as well as other climatic conditions. All these factors are important in understanding the take-up, metabolism and biotransformation of pesticides.

\section{Conclusion}

GC with quadrupole mass analyzer is a powerful technique in determination of pesticides at low levels. The results presented in this study showed that the samples analyzed were contaminated by pesticide residues, indicating that periodic monitoring programs are important to reduce exposure, accumulation and toxicity of pesticides. 


\section{Competing Interests}

The authors declare that there is no conflict of interests regarding the publication of this paper.

\section{References}

[1] Kachuri, L., Harris, M.A., MacLeod, J.S., Tjepkema, M., Peters, P.A. and Demers, P.A. (2017) Cancer Risks in a Population-Based Study of 70,570 Agricultural Workers: Results from the Canadian Census Health and Environment Cohort (CanCHEC). BMC Cancer, 17, 343. https://doi.org/10.1186/s12885-017-3346-x

[2] Prado, J.B., Mulay, P.R., Kasner, E.J., Bojes, H.K. and Calvert, G.M. (2017) Acute Pesticide-Related Illness among Farmworkers: Barriers to Reporting to Public Health Authorities. Journal of Agromedicine, 22, 395-405.

[3] Ambrus, Á. (2016) International Harmonization of Food Safety Assessment of Pesticide Residues. Journal of Agricultural and Food Chemistry, 64, 21-29. https://doi.org/10.1021/jf505854w

[4] Struciński, P., Góralczyk, K., Czaja, K., Hernik, A., Korcz, W. and Ludwicki, J.K. (2007) Consumer Risk Assessment in Case of Maximum Residue Levels (MRLs) Violations in Food. Roczniki Panstwowego Zakladu Higieny, 58, 377-388.

[5] Gutowski, L., Baginska, E., Olsson, O., Leder, C. and Kümmerer, K. (2015)Assessing the Environmental fate of S-Metolachlor, Its Commercial Product Mercantor Gold ${ }^{\star}$ and Their Photoproducts Using a Water-Sediment Test and in Silico Methods. Chemosphere, 138, 847-855. https://doi.org/10.1016/j.chemosphere.2015.08.013

[6] Salvia, M.-.V, Jrad, A.B., Raviglione, D., Zhou, Y. and Bertrand, C. (2017) Environmental Metabolic Footprinting (EMF) vs. Half-Life: A New and Integrative Proxy for the Discrimination between Control and Pesticides Exposed Sediments in Order to Further Characterise Pesticides' Environmental Impact. Environmental Science and Pollution Research, 1-7. https://doi.org/10.1007/s11356-017-9600-6

[7] World Health Organization (2009) The WHO Recommended Classification of Pesticides by Hazard and Guidelines to Classification 2009.

http://www.who.int/ipcs/publications/pesticides_hazard_2009.pdf

[8] European Commission (2015) Guidelines on Active Substances and Plant Protection Products-Food Safety.

https://ec.europa.eu/food/plant/pesticides/approval_active_substances/guidance_do cuments_en

[9] Department for Environment, Food \& Rural Affairs and Health and Safety Executive (2016) Expert Committee Pesticide Residues in Food Annual Report https://www.gov.uk/government/uploads/system/uploads/attachment_data/file/546 947/expert-committee-pesticide-residues-food-annual-report-2015.pdf

[10] Lu, J.L., Cosca, K.Z. and Del Mundo, J. (2010) Trends of Pesticide Exposure and Related Cases in the Philippines. Journal of Rural Medicine, 5, 153-164.

https://doi.org/10.2185/jrm.5.153

[11] Salvatore, A.L., Castorina, R., Camacho, J., Morga, N., López, J., Nishioka, M., et al. (2015) Home-Based Community Health Worker Intervention to Reduce Pesticide Exposures to Farmworkers' Children: A Randomized-Controlled Trial. Journal of Exposure Science \& Environmental Epidemiology, 25, 608-615. https://doi.org/10.1038/jes.2015.39

[12] Coskun, R., Gundogan, K., Sezgin, G.C., Topaloglu, U.S., Hebbar, G., Guven, M., et 
al. (2015) A Retrospective Review of Intensive Care Management of Organophosphate Insecticide Poisoning: Single Center Experience. Nigerian Journal of Clinical Practice, 18, 644-650. https://doi.org/10.4103/1119-3077.158962

[13] Sungur, M. and Güven, M. (2001) Intensive Care Management of Organophosphate Insecticide Poisoning. Critical Care (London, England), 5, 211-215. https://doi.org/10.1186/cc1025

[14] Qin, Y., Zhang, J., Li, Y., Wang, Q., Wu, Y., Xu, L., et al. (2017) Automated Multi-Filtration Cleanup with Nitrogen-Enriched Activated Carbon Material as Pesticide Multi-Residue Analysis Method in Representative Crop Commodities. Journal of Chromatography $A, 1515,62-68$. https://doi.org/10.1016/j.chroma.2017.08.009

[15] Pang, G.-F., Fan, C.-L., Liu, Y.-M., Cao, Y.-Z., Zhang, J.-J., Li, X.-M., et al. (2006) Determination of Residues of 446 Pesticides in Fruits and Vegetables by Three-Cartridge Solid-Phase Extraction-Gas Chromatography-Mass Spectrometry and Liquid Chromatography-Tandem Mass Spectrometry. Journal of AOAC International, 89, 740-771.

[16] Rezk, M.R., Abd El-Aleem, A.E.-A.B., Khalile, S.M. and El-Naggar, O.K. (2017) Determination of Residues of Diazinon and Chlorpyrifos in Lavender and Rosemary Leaves by Gas Chromatography. Journal of AOAC International. https://doi.org/10.5740/jaoacint.17-0193

[17] Pérez-Fernández, V., Mainero Rocca, L., Tomai, P., Fanali, S. and Gentili, A. (2017) Recent Advancements and Future Trends in Environmental Analysis: Sample Preparation, Liquid Chromatography and Mass Spectrometry. Analytica Chimica Acta, 983, 9-41. https://doi.org/10.1016/j.aca.2017.06.029

[18] Grimalt, S. and Dehouck, P. (2016) Review of Analytical Methods for the Determination of Pesticide Residues in Grapes. Journal of Chromatography A, 1433, 1-23. https://doi.org/10.1016/j.chroma.2015.12.076

[19] Danezis, G.P., Anagnostopoulos, C.J., Liapis, K. and Koupparis, M.A. (2016) Multi-Residue Analysis of Pesticides, Plant Hormones, Veterinary Drugs and Mycotoxins using HILIC Chromatography-MS/MS in Various Food Matrices. Analytica Chimica Acta, 942, 121-138. https://doi.org/10.1016/j.aca.2016.09.011

[20] Chen, X., Bian, Z., Hou, H., Yang, F., Liu, S., Tang, G., et al. (2013) Development and Validation of a Method for the Determination of 159 Pesticide Residues in Tobacco by Gas Chromatography-Tandem Mass Spectrometry. Journal of Agricultural and Food Chemistry, 61, 5746-5757. https://doi.org/10.1021/jf400887x

[21] Campos-Mañas, M.C., Plaza-Bolaños, P., Sánchez-Pérez, J.A., Malato, S. and Agüera, A. (2017) Fast Determination of Pesticides and Other Contaminants of Emerging Concern in Treated Wastewater using Direct Injection Coupled to Highly Sensitive Ultra-High Performance Liquid Chromatography-Tandem Mass Spectrometry. Journal of Chromatography A, 1507, 84-94. https://doi.org/10.1016/j.chroma.2017.05.053

[22] EU Pesticides Database European Commission [Internet]. http://ec.europa.eu/food/plant/pesticides/eu-pesticides-database/public/?event=pest icide.residue.selection\&language $=\mathrm{EN}$

[23] Chlornitrofen Toxicity, Ecological Toxicity and Regulatory Information [Internet]. http://www.pesticideinfo.org/Detail_Chemical.jsp?Rec_Id=PC38084

[24] Kitamori, S. (1996) [Biodegradation of Herbicide Chlornitrofen (CNP) and Mutagenicity of Its Degradation Products.] Fukuoka Igaku Zasshi Hukuoka Acta Medica, 87, 142-150. 
[25] EPN Chemical Profile 1/88 [Internet].

http://pmep.cce.cornell.edu/profiles/insect-mite/ddt-famphur/epn/insect-prof-epn. $\underline{\mathrm{html}}$

[26] Matsushita, T., Matsui, Y., Matsui, Y. and Inoue, T. (2005) Fate of Mutagenicity Produced during Anaerobic Biodegradation of the Herbicide Chlornitrofen (CNP). Journal of Environmental Science and Health, Part B, 40, 851-861. https://doi.org/10.1080/03601230500227541

[27] EPN Toxicity, Ecological Toxicity and Regulatory Information [Internet]. http://www.pesticideinfo.org/Detail_Chemical.jsp?Rec_Id=PC35087

[28] Ribeiro Begnini Konatu, F., Breitkreitz, M.C. and Sales Fontes Jardim, I.C. (2017) Revisiting Quick, Easy, Cheap, Effective, Rugged, and Safe Parameters for Sample Preparation in Pesticide Residue Analysis of Lettuce by Liquid Chromatography-Tandem Mass Spectrometry. Journal of Chromatography A, 1482, 11-22. https://doi.org/10.1016/j.chroma.2016.12.061

[29] Trevisan, M.T.S., Owen, R.W., Calatayud-Vernich, P., Breuer, A. and Picó, Y. (2017) Pesticide Analysis in Coffee Leaves using a Quick, Easy, Cheap, Effective, Rugged and Safe Approach and Liquid Chromatography Tandem Mass Spectrometry: Optimization of the Clean-Up Step. Journal of Chromatography A, 1512, 98-106. https://doi.org/10.1016/j.chroma.2017.07.033

[30] Martins, M.L., Kemmerich, M., Prestes, O.D., Maldaner, L., Jardim, I.C.S.F. and Zanella, R. (2017) Evaluation of an Alternative Fluorinated Sorbent for Dispersive Solid-Phase Extraction Clean-Up of the Quick, Easy, Cheap, Effective, Rugged, and Safe Method for Pesticide Residues Analysis. Journal of Chromatography A, 1514, 36-43. https://doi.org/10.1016/j.chroma.2017.07.080 